\title{
The Effects of Reducing Opportunity and Fraud Risk Factors on the Occurrence of Occupational fraud in Financial Institutions
}

Joon B Suha, Rebecca Nicolaides ${ }^{b}$, Richard Trafford ${ }^{\text {b }}$

${ }^{\text {a }}$ Institute of Criminal Justice Studies, University of Portsmouth, United Kingdom

${ }^{b}$ Faculty of Business and Law, University of Portsmouth, United Kingdom

* Corresponding author: Faculty of Business and Law, University of Portsmouth, University House, Winston Churchill Avenue, Portsmouth PO1 2UP, United Kingdom.

email: richard.trafford@port.ac.uk

Declarations of interest: none 


\title{
The Effects of Reducing Opportunity and Fraud Risk Factors on the Occurrence of Occupational Fraud in Financial Institutions
}

\begin{abstract}
Internal fraud has been attributed as one of the contributing factors for serious banking crises. Given that opportunity is the pre-eminent cause of white-collar crime, this study attempts to measure the relationships between the perceived 'opportunity reduction' and other fraud risk factors with regard to the 'likelihood of fraud occurrence' in financial institutions. For analysis, the study gathered 395 survey responses from South Korean financial sector. The results of logistic regressions of the study highlight that how to operate control mechanisms combining prevention and deterrence measures (the qualitative aspect of internal control), is more important for preventing fraud than the mere existence of many anti-fraud controls. In addition, the study discovers that the employees of the Korean financial institutions view that the risk of management override of controls is a more critical risk than collusion in their organization.
\end{abstract}

Key words: collusion; financial institution; fraud risk; management override; occupational fraud; opportunity

This research did not receive any specific grant from funding agencies in the public, commercial, or not-for-profit sectors. 


\section{Introduction}

Banking institutions within the financial system are very vulnerable to insider threats and require specialist risk management practices due to the severe negative externalities caused to society once they collapse. For example, in the USA, between 2008 and 2011, 355 commercial banks and 57 thrift institutions were declared insolvent and closed by the federal authorities. These failures will have cost up to $\$ 90$ billion to the economy (Tillman, 2015). In addition, numerous examples globally have demonstrated the internal vulnerabilities of the financial industry. Within the 5 year period from 2010 to 2014, there were 361 cases of employee embezzlement detected in Korean commercial banks, insurance and securities companies. The total loss of the employee embezzlement cases amounted to $£ 103$ million (Koo and Lee, 2016). In the UK, the fraudulent activities of former derivatives trader, Nick Leeson, caused the collapse of Barings Bank resulting in a $£ 850$ million loss (Button, 2008). In France, a trader, Jerome Kerviel at Société Générale caused a colossal loss of approximately $£ 4$ billion and was found guilty of forgery, unauthorised computer use and breach of trust (BBC News, 2010). Internationally, fraud and corruption within financial institutions have been attributed to be one of the most significant contributing factors for serious banking crises, such as the Savings \& Loan Debacle, and the Subprime Mortgage Crisis (FCIC, 2012; Friedrichs, 2010; Krugman and Wells, 2015; Tillman, 2015).

Within the white-collar criminology arena, Donald Cressey's Fraud Triangle proposed that there are three interrelated elements that must be present for someone to commit fraud: the incentive or pressure that creates a need for a person to want to commit the fraud, the opportunity that enables fraudsters to commit the act, and the ability to rationalize, prior to the act, justifications for the fraudulent behaviour (Cressey, 1972). Many studies have suggested that one of the biggest contributory factors for fraudulent activity, is having insufficient internal controls, as it provides fraudsters with the 'opportunity' to commit the crime (Albrecht et al., 2015; Dorminey et al., 2015, 2012, 2010; Rodgers et al., 2015). However, although 'opportunity' is the critical element of the triangle when focussing on risk control within an organization it has not been exposed to much empirical scrutiny, although it can be measured by the employees' perceived effectiveness of internal control in their organization (Dorminey et al., 2012, 2010). Internal control is defined as "a process effected by an entity's board of directors, management, and other personnel, designed to provide reasonable assurance regarding the achievement of objectives relating to operations, reporting, and 
compliance" (COSO, 2013: 3). Out of the three objectives, the present study is primarily focused upon its goal of compliance such as detecting and preventing occupational fraud, in the Korean financial sector. Moreover, it should be noted that there is a possibility that any control system can be bypassed or overridden by 'collusion' or 'management override', which is referred to as the Achilles' heel of fraud prevention (AICPA, 2016; Dorminey et al., 2012, 2010; Tipgos, 2002).

In this respect, this study attempts to measure the qualitative and quantitative aspects of 'opportunity reduction' and explores their effects on 'the occurrence of occupational fraud' in Korean financial institutions. Although there is a paucity of statistical studies on 'opportunity', it is suggested to be a root cause of all crime (Felson and Clarke, 1998). Following a discussion of the theoretical background and prior empirical studies, the development of hypotheses to be tested are articulated and an explanation of the survey method and the mapping of the regression variables are detailed. Finally, the findings of the study and their implications are discussed.

\section{Theoretical background and review of literature}

\subsection{Occupational fraud and fraud risk in the financial industry}

Fraud against organizations by employees is referred to as 'occupational fraud' and sometimes characterized as 'internal', 'insider' or 'employee' fraud (Boney et al., 2015; Edge, 2016; Gundez and Onder, 2013) or just called fraud (Murphy and Free, 2016). The world's largest anti-fraud organization, the Association of Certified Fraud Examiners (ACFE) defines occupational fraud as "the use of one's occupation for personal enrichment through the deliberate misuse or misapplication of the employing organization's resources or assets" (ACFE, 2012: 6-7). Occupational fraud entails three major categories: (1) asset misappropriation; (2) corruption; (3) fraudulent financial statements (ACFE, 2016, 2014, 2012; Albrecht et al., 2015; Wells, 1997). In the first two categories of crime, the employing organizations are the 'victims'. In the third category, whilst employees do conduct financial statement fraud, for example to achieve performance bonuses, or to hide asset misappropriation, these actions can also be performed by employees "on behalf of" the company. This would more correctly be classified as corporate crime (Clinard et al., 1994) as 
the general public and society become the 'victims' (Albrecht et al., 2015; Friedrichs, 2010; Holtfreter, 2005). Therefore, when fraud is referred to in this study, the concept of 'occupational fraud' as defined by the ACFE is adopted. However, it is acknowledged that although this study sets out to primarily address occupational fraud, it will encompass certain corporate fraud in this area.

The ACFE has been publishing the Report to the Nations on Occupational Fraud and Abuse biennially since 1996. According to the ACFE (2016) report, the typical company loses approximately 5 percent of its annual revenue to occupational fraud, and in the cases surveyed, the total loss exceeded $\$ 6.3$ billion, with an average loss per case of $\$ 2.7$ million. Occupational fraud is so common that nearly every organization experiences it (Albrecht et al., 2015). Therefore, it is vital for organizations to understand what increases the risk of fraud and what aids in preventing it.

Significantly, the ACFE report reveals that the banking and financial service industry globally had such a serious fraud problem that the number of cases in this industry ranked highest of all industries, which demonstrated the inherent risk in financial institutions (ACFE 2016, 2014, 2012). 'Risk' in the banking industry can be thought of as the potential loss that might result due to the occurrence of certain events. Risk exists because of the uncertainty associated with events that have the possibility to trigger financial loss. Financial risk in the banking industry includes credit risk, market risk and operational risk (Ghosh, 2012). Operational risk is defined as "the risk of loss resulting from inadequate or failed internal process, people and systems or from external events" (BCBS, 1998), and 'occupational fraud' is an example of operational risk (Ghosh, 2012). In order to prevent occupational fraud in the financial industry, the first step that should be taken is a risk assessment. An effective system of internal controls, with a good balance of preventive and detective measures, can significantly strengthen an organization's intolerance for occupational fraud. However, a system of internal controls cannot fully eradicate the risk, but well-designed and effective controls can deter the normal fraudsters by reducing the opportunity and increasing the perception of detection (ACFE, 2015).

\subsection{Reducing Opportunity}

The role of opportunity in promoting crime is underscored across disparate societies and cultures as can be seen in the various maxims of western and eastern societies; "opportunity 
makes the thief" is to the English what "seeing is wanting (견물생심)" is to the Koreans. Whilst most traditional criminological theories have focused on explaining why certain individuals are more likely to engage in criminal behavior, the 'opportunity' theories of crime have argued that "opportunity is a 'root cause' of crime" (Felson and Clarke, 1998: v). Theories of opportunity highlight the need to change the environment in which crime can occur in order to affect the assessments made by potential offenders concerning the costs and benefits associated with committing particular offences (Clarke, 1997: 5). Therefore, the theories of 'crime settings' rest on the principle that easy or tempting opportunities, entice people into criminal action, and therefore crime can be prevented by eliminating opportunities. These theories are also referred to within environmental criminology and include routine activity theory, the rational choice model and situational crime prevention strategy (Felson and Clarke, 1998; Haelterman, 2016; Tunley et al., 2018).

The routine activity theory assumes that for crime to occur, there must be a merging in time and space of three critical elements: a 'likely offender', a 'suitable target', and the 'absence of a capable guardian'. These three elements are commonly known as the Basic Crime Triangle (Felson and Clarke, 1998). Rational choice theory is based upon the expected utility principle in economics whereby it is posited that people will make rational decisions based on the extent to which they expect the choice to maximize their benefits or minimize losses. If the monetary or personal costs of exploiting a criminal opportunity are perceived as greater than the expected gain, the offender will cease the activity (Akers and Sellers, 2009). This rational choice model is also closely linked to situational crime prevention, which is explicitly designed to reduce crime opportunities by (1) increasing the perceived effort of crime, (2) increasing the perceived risk to a potential offender, (3) reducing the anticipated rewards, (4) reducing provocations, and (5) removing excuses (Clarke, 2005; Felson and Clarke, 1998).

A further and more recent development in the criminogenic theory corpus is Situational Activity Theory (Lokanan, 2017). This espouses the interplay between an employee's morality and the moral context in which they work, thereby bringing into play the environmental factors and psychosocial interactions, within what may be a normally functioning organization which has developed to embrace deception and manipulation within its normative activities. This has a particular resonance where management fraud may be active and chimes with Rae and Subramaniam's (2008) "perceptions of organizational justice" impacting an employee's motivation for fraud. This may be a key driver within the "opportunity" for management 
override, which will be considered later. All these situational pressures act to create opportunity whether by physicality or as an environmentally moral acceptability.

Within the opportunity crime theory context Cressey's Fraud Triangle model characterises 'perceived opportunity' as a critical constituent of occupational fraud (Cressey, 1972). The Fraud Triangle is a framework which has over time been "translated" and defined by practitioners (Morales et al., 2014) to focus on controllable risks, ergo the mitigation of 'opportunity risk' by the institution of internal controls becomes the overarching prevention and detection strategy. Lokanan (2018) reinforces the practitioner thematic, by suggesting that the Fraud Triangle provides a useful aid to understanding why employees commit fraud but it is not a general scientific theory of crime. This further underlines the practitioner model perspective whereby the Fraud Triangle can be adapted for use in differing operational contexts to direct investigations (Lokanan, 2018: Morales et al. 2014). Furthermore, Cressey did not directly address the impact of sociocultural issues in his work, as he perceived fraud as an individual person phenomena and although social issues may augment the other two legs of the triangle namely non-shareable financial problem or 'pressure' and 'rationalisation' these are generally not transparently assailable by organisations trying to prevent internal fraud (Jans et al. 2010). Therefore, it is the reduction of opportunity that becomes the critical focus of organisations, which is consonant with the opportunity crime theories discussed earlier. Opportunity in the Fraud Triangle is commonly defined as where (1) a control weakness is present, and (2) the likelihood of being caught is remote (Dorminey et al., 2012: 558). In order to reduce opportunity, increasing the perceived probability of detection and punishment is emphasized (ACFE, 2015; Albrecht et al., 2015; Dorminey et al., 2012, 2010; Kumar et al., 2018: Rae and Subramaniam, 2008). Therefore, it is vital to assess and secure the effectiveness of controls with respect to detecting and preventing occupational fraud. There can be various proxy measures to gauge such effectiveness. One of the most common methods used, is to compare the median loss and detection period (ACFE, 2016, 2014, 2012), or the employees' perception of the effectiveness of anti-fraud controls (Ahmad and Norhashim, 2008; Hunziker, 2017; Vu, 2016), and between one organization which is implementing a specific measure, such as a whistle-blowing program, and another organization, which is not (Tunley et al., 2018).

Despite the critical importance of 'opportunity reduction', however, there are not many empirical studies which have been conducted to detect the relationship between 'opportunity 
reduction' and the likelihood of fraud occurrences in the extant literature. The current study will highlight this area of research and underline its importance. In addition, this study also dissected 'opportunity reduction' into two aspects; quantitative (number of anti-fraud controls) and qualitative (effectiveness of controls) dimensions to see their respective effect on the occurrence of occupational fraud in Korean financial institutions. This being a precursor to testing the hypothesis that: perfunctory or the mere existence of controls (the number of controls), is not effective in preventing fraud unless such controls function effectively to eliminate opportunity (Albrecht et al., 2015; Dorminey et al., 2012; Kabue and Aduda, 2017; Said et al., 2017; Tipgos, 2002).

\subsection{Management override and collusion}

Management override and collusion are two of the most severe risks to counter-fraud effort, and are often referred to as 'the Achilles heel' of fraud prevention (Dorminey et al., 2012, 2010; AICPA, 2016). 'Management override' refers to "the ability of management or those charged with governance to manipulate accounting records and prepare fraudulent financial statements by overriding these controls, even where the controls might otherwise appear to be operating effectively" (IFAC, 2012: 162-163). Internal controls are sometimes regarded as ineffective in deterring management fraud because some senior members of a company, such as the CEO or CFO, consider the overriding of internal controls as a way of attaining corporate business objectives, such as success and profit. In other words, the senior management of a company govern the 'internal control' system, and thereby can egregiously manipulate it. This is conceptually reinforced by the idea of the Fraud Diamond (Wolfe and Hermanson, 2004), which introduced the fourth element of 'capability' to the Fraud Triangle. For example, Enron, where a massive financial statement fraud had occurred, the directors voted twice to suspend the corporate code of ethics, thus allowing them to set up the partnership special purpose vehicles (SPVs) that finally led to the demise of the company (Tipgos, 2002). AICPA (2016) goes further in their report in suggesting that the majority of the critically significant fraud cases in the last 50 years were enacted by senior members of management bypassing or overriding seemingly effective systems.

The other Achilles heel of fraud prevention, 'collusion', has been found to have a positive correlation with the amount of financial damage caused by fraud (ACFE, 2016). Free and Murphy (2015) investigated why individuals co-offend in fraud, thus identifying three 
archetypes; (1) individual-serving functional bonds; (2) organizational-serving functional bonds; and (3) affective bonds according to two criteria (the primary beneficiary and the qualitative nature of tie). Because the Fraud Triangle normally posits a single atomized individual, it is potentially not as effective in explaining collusive fraud (Akelola, 2012; Dorminey et al., 2012; Free and Murphy, 2015). Therefore, the elaboration of the Fraud Triangle should place a greater emphasis on collusive fraud especially as by creating a collusive group, opportunity can be created (Free and Murphy, 2015), and indeed further enhanced through the group by the potential obviation of 'capable guardians'. However, despite the potentially devastating impact of 'collusion' and 'management overrides', empirical studies of these factors in fraud are sparingly considered in the extant literature (Lokanan, 2017). In this respect, the significance of the present study lies in opening this line of research enquiry to wider consideration.

\subsection{Hypotheses Formation}

Within the contextual framework articulated, enveloping fraud risk, internal control and the reduction of opportunity for fraud, the following hypotheses are postulated:

Hypothesis 1: If the number of anti-fraud controls existing in the organization is preponderant (quantitative aspect of opportunity reduction), then the odds of reporting the occurrence of occupational fraud in their bank are smaller.

Hypothesis 2: If an employee agrees that opportunity is reduced more effectively in the organization (qualitative aspect of opportunity reduction), then the odds of reporting the occurrence of occupational fraud in their bank are smaller.

Hypothesis 3a: If an employee agrees that management override is a major contributing factor of occupational fraud in the organization today, then the odds of reporting the occurrence of occupational fraud in their bank are larger.

Hypothesis $3 b$ : If an employee agrees that collusion is a major contributing factor of occupational fraud in the organization today, then the odds of reporting the occurrence of occupational fraud in their bank are larger.

These are specifically tested within the Korean financial industry by employing a survey questionnaire. 


\section{Methods}

\subsection{Sample and procedure}

For data collection, a questionnaire was constructed and distributed using a quota sampling method to employees in the Korean financial institutions during the period from June to October 2016. The survey questionnaire utilized a web-based platform easily accessible via social networks and email services. The Korean Anti-money Laundering (AML) Working Groupi, which was founded to educate the employees on AML was approached. After consideration and approval by the ethics committee, permission was granted to utilize the last-known contact details from the group. An informed consent form was posted on the introductory webpage notifying that participation was voluntary and confidential. A total of 444 responses were collected, with 49 of these incomplete, therefore reducing the sample total to 395 . Six different types of depository financial institutions, as defined by KFSS (2017) and The Bank of Korea (2011), were included in the sample; nationwide banks, regional banks, local agricultural $\&$ fishery cooperatives, community credit cooperatives, credit unions, and savings banks. Within this categorisation, the survey responses were coded and classified, as reflected in Table 1.

Insert Table 1 here.

\subsection{Measures}

Given the potential in survey research for common method variance (CMV) occurrence this survey incorporates a number of techniques, recommended in the literature (Chang et al., 2010: Podsakoff et al., 2003), to reduce the incidence and impact of such variances. Whilst ideally, the independent and dependent variables should be collected from different sources, this was not possible in this survey as the responses are anonymous and therefore differing submission sources would not be able to be linked for analysis. However, anonymity can aid in obtaining unbiased answers to the questions posed, rather than generating answers respondents perceive as desired (Podsakoff et al., 2003). Furthermore, a number of the 
questions required factual yes or no answers, which were then aggregated in the results analysis with perception questions following these dichotomous questions. This decomposed questions into more straightforward and focused elements (Podsakoff et al., 2003) and separated the criterion question or dependent variable from the predictor or independent variable perception questions, thus enabling a psychological separation and reduction of bias. In addition, the survey questions were drafted in clear non-complex language and syntax and pilot tested to ensure clarity and ease in understanding.

The data collected was evaluated within the analytical framework of the model:

$$
Y_{i}=f\left(\beta_{n} D_{n}+\beta_{1} X_{1}+\beta_{2} X_{2}+\beta_{3} X_{3}+\beta_{4} X_{4}\right)
$$

Where:

$Y_{i}=$ The occurrence of occupational fraud.

$D_{n}=$ Organizational level control variables.

$X_{1}=$ The number of anti-fraud controls.

$X_{2}=$ The perceived opportunity reduction.

$X_{3}=$ The perceived contribution of management override.

$X_{4}=$ The perceived contribution of collusion.

\subsubsection{Dependent variable}

To capture the dependent variable, 'the occurrence of occupational fraud', a dichotomous variable was developed by asking respondents whether occupational fraud had been found to have occurred in their financial institution within the last five years. $(1=$ occurred, $0=$ not occurred; mean $=0.413$ )

\subsubsection{Organizational level control variables}

The organizational control variables encompass the size and type of the financial institution (Coleman, 1987; Wheeler and Rothman, 1982) and the department of the survey participant in the bank. The total number of employees was used to create the variable 'organizational size' which was dummy coded ( 1 = more than 5,000 employees, less than 5,000 employees $=0$; mean $=0.33)$ and the department in the organization is also dummy coded; working in the 
internal control or support department $(=1$, others $=0$, mean $=0.40)$. Within the model, the nationwide banks are designated as the reference group and the other 5 types of different depository financial institutions were all dummy coded; regional banks ( $=1$, non-regional banks $=0 ;$ mean $=0.07)$, local agricultural \& fishery cooperatives $(=1$, non-local agricultural \& fishery cooperatives $=0$; mean $=0.21)$, community credit cooperatives $(=1$, non-community credit cooperatives $=0 ;$ mean $=0.08)$, credit unions $(=1$, non-credit unions $=0 ;$ mean $=0.15)$ and savings banks $(=1$, non-savings banks $=0$, mean $=0.05)$.

\subsubsection{Independent variables}

The first independent variable, 'the number of anti-fraud controls' was measured by asking the respondent whether specific controls existed in their bank and aggregating the positive responses to produce a total number. The 14 specific anti-fraud controls were adopted from Giles (2012); (1) the segregation of duties ( 1 = exist, 0 = non-exist; mean $=0.90)$, (2) the authorization limits $(1=$ exist, $0=$ non-exist; mean $=0.94)(3)$ criminal history pre-screening $(1$ $=$ exist, $0=$ non-exist; mean $=0.59)(4)$ credit pre-screening $(1=$ exist, $0=$ non-exist; mean $=$ $0.61)(5)$ certification pre-screening $(1=$ exist, $0=$ non-exist; mean $=0.56)(6)$ mandatory vacation ( 1 = exist, 0 = non-exist; mean $=0.70$ ), (7) affirmation of a published anti-occupational fraud statement $(1=$ exist, $0=$ non-exist; mean $=0.75)$, (8) internal control assessment $(1=$ exist, $0=$ non-exist; mean $=0.93)$, (9) anti-occupational fraud training $(1=$ exist, $0=$ non-exist; mean $=0.94),(10)$ employee support program $(1=$ exist, $0=$ non-exist; mean $=0.77)$, surprise audit ( $1=$ exist, $0=$ non-exist; mean $=0.88)$, (12) fraud hot-line $(1=$ exist, $0=$ nonexist; mean $=0.83$ ), (13) computerized constant monitoring ( $1=$ exist, $0=$ non-exist; mean $=$ $0.92)$, (14) reward program for whistle-blowers ( 1 = exist, $0=$ non-exist; mean $=0.52$ ).

The second independent variable, 'the perceived opportunity reduction' was measured against ten items using a 5-point Likert scale ( 1 = strongly disagree, 5 = strongly agree) adapted from the opportunity reduction checklist of Dorminey et al. (2010). The reliability of the scale was very high with a Cronbach's a of 0.951 . The ten items are (1) "Internal control system is properly designed" (mean $=3.71$, standard deviation $=0.95)$, (2) "Internal control system is in good operation as designed" (mean $=3.66$, standard deviation $=0.96$ ), (3) "Continuous monitoring program in our bank is in good operation" ( mean $=3.79$, standard deviation $=$ 0.99), (4) "Auditing tools and programs in our bank are effective" (mean $=3.70$, standard deviation = 1.01), (5) "Occupational fraudsters who are caught receive appropriate punishment" (mean $=3.70$, standard deviation $=1.08)$, (6) "Open communications with 
employees, vendors, suppliers, and customers for countering occupational fraud are in good operation" ( mean $=3.36$, standard deviation $=1.05)$, (7) "Employee activity is properly monitored" (mean $=3.54$, standard deviation $=0.97$ ), (8) "Effective fraud hot-line is operating" $($ mean $=3.20$, standard deviation $=1.07),(9)$ "Protection of whistle blowers is good" $($ mean $=$ 2.98 , standard deviation $=1.18),(10)$ "Contractual parties are properly monitored" (mean = 3.34 , standard deviation $=1.02$ ). The variable of 'perceived opportunity reduction' was created by averaging the ten items.

The third independent variable, 'the perceived contribution of management overrides' was measured against a single item with 5-point Likert scale ( 1 = strongly disagree, 5 = strongly agree) adapted from the KPMG (2007) study. The perception was based upon the statement: "In my opinion, management overrides of internal control enable occupational fraud to occur most within the organization today" (mean $=3.12$, standard deviation $=1.17$ ).

The final independent variable, 'the perceived contribution of collusion' was evaluated using 3 items on the 5 -point Likert scale ( 1 = strongly disagree, $5=$ strongly agree) adapted from the KPMG (2007) study. The reliability of the scale was high with a Cronbach's a of 0.876 . The three items are (1) "In my opinion, the collusion between ordinary employees and customers enables occupational fraud to occur most within the organization today" (mean $=2.72$, standard deviation = 1.10), (2) "In my opinion, the collusion between management and customers enables occupational fraud to occur most within the organization today" (mean = 2.83 , standard deviation = 1.15), (3) "In my opinion, the collusion between management and ordinary employees enables occupational fraud to occur most within the organization today" ( mean $=2.70$, standard deviation $=1.15)$. The variable of 'collusion' was created by aggregating the three items and then averaging the result.

\subsection{Analysis and descriptive statistics}

To predict the odds of the occurrence of occupational fraud in the depository financial institutions, logistic regression was utilized, which is used for predicting a discrete outcome, generally the dichotomous dependent variable. Logistic regression is regarded as more flexible because it does not need to meet the requirement of the predictor variable conditions, which are the normal distribution, linear relationship, and equal variance assumptions (Ho, 2014: 383). In this study, the dependent variable was the binary variable, where occupational fraud had occurred (1) or did not occur (0) in a financial institution within the last five years. 
Insert Table 2 here.

Insert Table 3 here.

To test the hypotheses of 1 to 2 , 3a and $3 \mathrm{~b}$, a series of logistic regression was conducted and Table 4 below presents the results of the logistic regressions. To interpret logistic regression coefficients, it is more pertinent to understand the odds ratio $((\pi /(1-\hat{\pi}))$ rather than the coefficient $(\beta)$. The logistic regression coefficient $(\beta)$ shows the changes in the predicted logged odds of experiencing an event for a one-unit change in the independent variables. The second interpretation comes from transforming the logistic regression coefficients $(\beta)$ so that independent variables affect the odds rather than the logged odds of the dependent variable. To find the effect on odds, it is necessary to take the exponent of the $\beta$. For the exponentiated coefficient which is called the odds ratio, an exponentiated coefficient of 1 leaves the odds unchanged, an exponentiated coefficient greater than 1 increases the odds, and an exponentiated coefficient smaller than 1 decreases the odds. In terms of a formula, the exponentiated coefficient (odds ratio) minus 1 and times 100 gives the percentage increase or decrease due to a one-unit change in the independent variable (Pampel, 2000: 23).

$$
\% \text { change }=\{(\text { odds ratio })-1\}^{*} 100
$$

\section{Results and findings}

\section{Insert Table 4 here.}

In model 1 in which only control variables were included, three variables were statistically significant predictors of the odds of the employee reporting the occurrence of occupational fraud; (1) working in the internal control or support department $(p=.000)$, (2) large organizational size $(p=.003)$, (3) financial institution type $(p=.000)$. The findings showed that, 
the odds of reporting the occurrence of occupational fraud of the employee who is working in the internal control or support department (odds ratio $=3.07$ ) are 3.07 times as large or 207 percent larger for the odds of whom is not working for either department. The variable of organizational size predicts that the odds of the employee working in a financial institution with more than 5,000 employees (odds ratio $=3.15$ ) are 3.15 times as large or 215 percent larger than for those who are working for a financial institution which has less than 5,000 employees. In terms of the type of financial institution, compared to nationwide banks (the reference group), the odds of reporting the occurrence of occupational fraud of the employee working for community credit cooperatives (odds ratio $=0.07$ ) are 0.07 times as small or 93 percent smaller $((0.07-1) * 100)$ than those who are working for nationwide banks. In a similar vein, the odds of the employee of reporting the occurrence of occupational fraud of the employee working for credit unions (odds ratio $=0.15$ ) are 0.15 times as small or 85 percent smaller $((0.15-1) * 100)$ than for those who are working for nationwide banks. Throughout all models, these control variables were statistically significant at an alpha level of 1 percent.

In model 2, the quantitative aspect of internal control was considered, which is the number of anti-fraud controls in the financial institution, but no significant effect was found ( $p=.416$ ). Consistent with this, no significant effect was found in all models thus rejecting hypothesis 2 . In model 3, the independent variable of 'the perceived opportunity reduction' was evaluated (odds ratio $=0.68$ ) and found to have a statistically significant effect $(p=.021)$ Therefore, the odds of reporting the occurrence of occupational fraud in their financial institution are 32 percent smaller $((0.68-1) * 100)$ for an additional one-unit increase of the perceived opportunity reduction. This result supported hypothesis 2 at an alpha level of 5 percent.

Finally, in model 4, 'perceived contribution of management override' and 'collusion' to perceived fraud occurrence were tested. In the results, only the variable of 'perceived management override' (odds ratio $=1.39$ ) showed a statistically significant effect supporting hypothesis $3 a(p=.010)$. This shows that, the odds of reporting the occurrence of occupational fraud in their financial institution are 1.39 times as large or 39 percent greater for an additional one-unit increase of the perceived management override. However, as a variable, collusion was not significant at the $5 \%$ confidence level $(p=.137)$. Thereby, failing to support hypothesis 3b. 


\section{Discussion and Conclusion}

The necessity for more effective 'risk management' is imperative judging by the stark increase in high profile financial scandals such as the collapse of Lehman Brothers, the bail out of insurance company AIG, and the US government takeover of mortgage giants Freddie Mac and Fannie Mae in the wake of the Subprime mortgage crisis. Many studies of the banking crises have concluded that occupational fraud and abuse were prominent causal factors (Calavita et al., 1997: 31; FDIC, 1997: 34; Tillman, 2015). Therefore, it is pivotal for future stability in the sector that risk is successfully managed from within the financial industry (Friedrichs, 2010; Krugman and Wells, 2015). In this context, the insiders of financial institutions would have a significant impact on the financial system not only as 'capable guardians' but also as 'likely offenders' (Button, 2008; Felson, 2002). Therefore, within the constraints of this study, risk management is investigated in terms of protecting banking institutions from the constant endogenous vulnerability of occupational fraud.

The evaluative analysis revealed statistically significant findings; firstly, the qualitative aspect of opportunity reduction through the perceived effectiveness of anti-fraud controls is negatively associated with the odds of reporting an historic occurrence of occupational fraud, whilst the quantitative aspect of opportunity reduction (the number of anti-fraud controls) is not. This is the most significant finding in the study, which highlights that how control mechanisms are operationalized is more important for preventing fraud than the mere existence of anti-fraud controls thus supporting the principle of substance over form and affirming that stale controls are of no-use. This also aligns closely with Cressey's expression of the opportunity factor as 'perceived opportunity' (Cressey, 1972), as employees would be more cognisant of how effective a form of internal control is when evaluating such a perception (Morales et al., 2014). Thirdly, the employees' perceived belief that the potential for management overrides is positively associated with the odds of reporting the occurrence of occupational fraud whilst the perceived contribution of collusion is not. This underlines the financial institutions employees' perception that management overrides are the more serious risk factor.

The control variable of employees working in the internal control or support department was positively associated with the odds of reporting the occurrence of occupational fraud with high statistical significance $(p<0.001)$. Information asymmetry can explain the reason for this 
because the internal control or support department is generally located in the headquarters of the financial institution with centralized information reported from the branch network. The consolidated information enables the employees who are working in either department to know much more about the information on occupational fraud, which is sometimes regarded as sensitive and confidential due to possible reputational damage to the organization (Button, 2008). In addition, large organizational size was also positively associated with the odds of reporting the occurrence of occupational fraud at a one percent confidence level $(p<0.01)$. A study by Barnes and Webb (2007) similarly found that the vulnerability to internal fraud increased the greater the size of an organization. This can be explained in terms of Routine Activity Theory (Felson, 2002). If there are increasingly attractive targets (assets) and motivated offenders (employees) in a large financial institution, the institution is more likely to suffer from occupational fraud. Another possible reason is that small and medium sized financial institutions generally have fewer controls (capable guardian), which has led to a reduced incidence of detection in comparison with larger banking institutions, suggesting that more occupational fraud is hidden and ongoing because of the staffing and budget limitations on counter-fraud activity (Bussmann and Werle, 2006; Johansson and Carey, 2016). This hypothesis should also remain an area for future research. The results of this study also align with, and are resonant of, a pilot survey study conducted in Australia (Kumar et al., 2018) where it was found that a "slack" organizational culture relative to fraud can create a rationalization for occupational fraud.

The present study also has several limitations. First, one of the significant control variables, 'organizational size' was based on the number of employees employed in an organization. This was selected as a measure because as well as being a valid measure of size (Child, 1973) it also represents a measure of control complexity in organizations (Bedford and Malmi, 2015). However, other aspects related to an organization could be considered such as revenues and profitability of banks. Second, the occurrences of occupational fraud in a financial institution in the last five years were taken from the survey responses as the dependent variable. Nonetheless, categorizing the variable based on the amount of loss incurred from the fraud statistics would enable an additional understanding of scale. However, occupational fraud is regarded as so sensitive that it is very difficult to obtain fraud statistics in the Korean banking industry (Suh et al, 2018). Furthermore, the archival data, such as revenues, profitability and fraud losses of banks could not be gained without potentially compromising respondents' anonymity. Given the limitation of data access, the survey method of directly asking the binary 
questions about fraud occurrences was the least worst option for gathering such delicate data without causing harms to the participants (British Psychology Society, 2010). As already discussed in section 3.2, with all surveys of this type there is a potential for CMV to impact upon the results and therefore further studies of this nature, in other geographic areas would enable further validating perspectives and insights to be drawn.

To sum, the study showed that eliminating perceived opportunity is significantly associated with the decreased likelihood of fraud occurrence in organizations. Previous studies simply defined fraud opportunity as (1) internal controls are weak and (2) the chances of detection and punishment are remote (Dorminey et al., 2012: 558). However, there has been no further research regarding the relationship between the perceived opportunity reduction and occurrence of fraud. To fill the gap, opportunity reduction in this study was approached in a novel way by measuring 10 items which focused on the key perspectives of strengthening internal control and enhancing deterrence (Dorminey et al., 2012, 2010). This could be very significant in the fraud literature, because some studies have posited that opportunity merely determines the time and place of crime, but does not cause it, then the expected result of reducing opportunity would simply be to displace crime (Wortley, 2010). However, this study has succeeded in providing statistical evidence that perceived opportunity reduction is negatively associated with the odds of the employee reporting the occurrence of occupational fraud in the organization. Therefore, the current study concludes that counter-fraud effort and activity should focus on eliminating fraud opportunities by combining prevention and deterrence measures which are shown to be valid by the study.

\section{References}

AICPA, 2016. Management Override of Internal Control: The Achilles' Heel of Fraud Prevention. AICPA, New York.

Ahmad, Z., Norhashim, M., 2008. The control environment, employee fraud and counterproductive workplace behaviour: An empirical analysis. Communications of the IBIMA 3, 145-155.

Akelola, S., 2012. Fraud in the banking industry: a case study of Kenya. Unpublished doctoral thesis, Nottingham Trent University, Nottingham. 
Akers, R. L., Sellers, C.S., 2009. Criminological theories: Introduction, evaluation, and application, sixth ed. Oxford University Press, New York.

Albrecht, W., Albrecht, C.O., Albrecht, C.C., Zimbelman, M., 2015. Fraud Examination, fifth ed. Cengage Learning, Boston.

Association of Certified Fraud Examiners (ACFE), 2012. Report to the Nations on Occupational Fraud and Abuse. ACFE, Austin.

Association of Certified Fraud Examiners (ACFE), 2014. Report to the Nations on Occupational Fraud and Abuse. ACFE, Austin.

Association of Certified Fraud Examiners (ACFE), 2015. Fraud Examiners Manual, International ed. ACFE, Austin.

Association of Certified Fraud Examiners (ACFE), 2016. Report to the Nations on Occupational Fraud and Abuse. ACFE, Austin.

Barnes, P., Webb, J., 2007. Organisational susceptibility to fraud and theft, organizational size and the effectiveness of management controls: some UK evidence. Managerial and Decision Economics 28(3), 181-193.

Basel Committee on Banking Supervision (BCBS), 1998. Operational Risk Management. BIS, Basel.

BBC News, 2010. Societe Generale trader Kerviel jailed for three years. http://www.bbc.co.uk/news/business-11474077 (accessed 11 May 2018).

Bedford, D.S., Malmi, T., 2015. Configurations of control: An exploratory analysis. Management Accounting Research 27, 2-26.

Bonny, P., Goode, S., Lacey, D., 2015. Revisiting employee fraud: gender, investigation outcomes and offender motivation. Journal of Financial Crime 22(4), 447-467.

British Psychology Society (BPS), 2010. Code of Human Research Ethics. http://www.bps.org.uk/sites/default/files/documents/code_of_human_research_ethics.pd (accessed 30 Sept 2018).

Bussmann, K. D., Werle, M.M., 2006. Addressing Crime in Companies: First Findings from a Global Survey of Economic Crime. British Journal of Criminology 46(6), 1128-1144. 
Button, M., 2008. Doing security: critical reflections and an agenda for change. Palgrave Macmillan, London.

Calavita, K., Pontell, H.N., Tillman, R., 1997. Big money crime: Fraud and politics in the savings and loan crisis. University of California Press, Berkeley.

Chang, S., Witteloostuijn, A., Eden, L., 2010. From the Editors: Common Method Variance in international business research. Journal of International Business Studies 41, 178-184.

Child, J., 1973. Predicting and Understanding Organization Structure. Adminstrative Science Quarterly 18(2), 168-185.

Clarke, R., 1997. Situational Crime Prevention. Successful Case Studies, second ed. Clarke, R., (Ed.) Harrow and Heston, New York.

Clarke, R. V., 2005. Seven misconceptions of situational crime prevention. In Tilley, N. (Ed.), Handbook of crime prevention and community safety. Willan Publishing, Cullompton, pp. 39-70.

Clinard, M.B., Quinney, R., Wildman, J., 1994. Corporate criminal behavior. In Clinard, M.B., Quinney, R., Wildman, J., (Eds), Criminal Behavior Systems: A Typology Reviewed, third ed. Anderson Publishing, Abingdon, pp. 191-215.

Coleman, J.W., 1987. Toward an Integrated Theory of White-Collar Crime. American Journal of Sociology 93(2), 406-439.

COSO., 2013. Internal Control - Integrated Framework. https://www.coso.org/Documents/990025P-Executive-Summary-final-may20.pdf (accessed 11 May 2018).

Cressey, D., 1972. Other People's Money: The Social Psychology of Embezzlement. Wadsworth Publishing Company, Belmont.

Dorminey, J. W., Fleming, A.S., Kranacher, M., Riley, M.A., 2010. Beyond the fraud triangle. The CPA Journal 80(7), 17-23.

Dorminey, J.W., Fleming, A.S., Kranacher, M., Riley, R.A., 2012. The Evolution of Fraud Theory. Issues in Accounting Education 27(2), 555-579.

Edge, K., 2016. Preventing Insider Fraud-Bank industry. Tenn. BJ 52, 28-30. 
Federal Deposit Insurance Corporation (FDIC), 1997. Bank Examination and Enforcement, 1980-1994. In: History of the Eighties - Lessons for the Future: Proceedings of the FDIC Symposium.

Felson, M., 2002. Crime and Everyday Life, third ed. Sage Publication Ltd, London.

Felson, M., Clarke, R., 1998. Opportunity Makes the Thief: Practical theory for crime prevention, Police Research Series 98, B. Webb, (Ed.). Home Office, Policing and Reducing Crime Unit, London.

Financial Crisis Inquiry Commission (FCIC), 2011. Final Report of the National Commission on the Causes of the Financial and Economic Crisis in the United States. US Government Printing Office.

Free, C. Murphy, P., 2015. The ties that bind: The decision to co-offend in fraud. Contemporary Accounting Research 32(1), 18-54.

Friedrichs, D., 2010. Trusted criminals: white collar crime in contemporary society, fourth ed. Wadsworth Cengage Learning, South Melbourne.

Ghosh, A., 2012. Managing risks in commercial and retail banking. John Wiley, Hoboken.

Giles, S., 2012. Managing Fraud Risk: A Practical Guide for Directors and Managers. John Wiley $\&$ Sons Ltd., Chichester.

Gunduz, M., Önder, O., 2013. Corruption and Internal Fraud in the Turkish Construction Industry. Science and Engineering Ethics 19(2), 505-528.

Haelterman, H., 2016. Crime Script Analysis: Preventing Crimes Against Business. Palgrave Macmillan, London.

Ho, R., 2014. Handbook of Univariate and Multivariate Data Analysis with IBM SPSS, second ed. CRC Press, Boca Raton.

Holtfreter, K., 2005. Is occupational fraud typical white-collar crime? A comparison of individual and organizational characteristics. Journal of Criminal Justice 33(4), 353-365.

Hunziker, S., 2017. Efficiency of internal control: evidence from Swiss non-financial companies. Journal of Management \& Governance 21(2), 399-433. 
IFAC, 2012. The Auditor's Responsibilities Relating to Fraud in an Audit of Financial Statements, International Standard on Auditing 240. IFAC Handbook of International Quality Control, Auditing, Review, Other Assurance.

Jans, M., Lybaert, N., Vanhoof, K., 2010. Internal fraud risk reduction: Results of a data mining case study. International Journal of Accounting Information Systems, 11(1), 17-41.

Johansson, E., Carey, P., 2016. Detecting fraud: The role of the anonymous reporting channel. Journal of Business Ethics 139(2), 391-409.

Kabue, L.N., Aduda, D.J., 2017. Effect of Internal Controls on Fraud the Detection and Prevention Among Commercial Banks in Kenya. European Journal of Business and Strategic Management 2(1), 52-68.

Koo, K., Lee, S., 2016. Identifying the influence of age on the public servants' embezzlement crime. The Korean Journal of Corruption Studies 21(3), 5-30.

Korean Financial Supervisory Services (KFSS)., 2017. Korean Bank Statistics, (In Korean). http://www.fss.or.kr/fss/kr/main.html (accessed 11 May 2018).

KPMG, 2007. Profile of a Fraudster Survey 2007. KPMG International, Switzerland.

Krugman, P., Wells, R., 2015. Economics, fourth ed. Worth Publishers, New York.

Kumar, K., Bhattacharya, S., Hicks, R., 2018. Employee perceptions of organization culture with respect to fraud - where to look and what to look for. Pacific Accounting Review 30(2), 187198.

Lokanan, M., 2017. Theorizing Financial Crimes as Moral Actions. European Accounting Review. DOI: $10.1080 / 09638180.2017 .1417144$

Lokanan, M., 2018. Informing the Fraud Triangle: Insights from Differential Association Theory. Journal of Theoretical Accounting Research 14(1), 55-98.

Morales, J., Gendron, Y., Guénin-Paracini, H., 2014. The construction of the risky individual and vigilant organization: A genealogy of the fraud triangle. Accounting, Organizations and Society $39,170-194$

Murphy, P., Free, C., 2016. Broadening the fraud triangle: Instrumental climate and fraud. Behavioral Research in Accounting 28(1), 41-56. 
Pampel, F. C., 2000. Logistic regression: A primer (Vol. 132). Sage Publications, Thousand Oaks.

Podsakoff, P. M., MacKenzie, S. B., Lee, J.-Y., Podsakoff, N. P., 2003. Common method biases in behavioural research: A critical review of the literature and recommended remedies. Journal of Applied Psychology 88(5), 879-903.

Rae, K., Subramaniam, N., 2008. Quality of internal control procedures: Antecedents and moderating effect on organisational justice and employee fraud. Managerial Auditing Journal 23(2), 104-124.

Rodgers, W., Söderbom, A., Guiral, A., 2015. Corporate Social Responsibility Enhanced Control Systems Reducing the Likelihood of Fraud. Journal of Business Ethics 131(4), 871-882.

Said, J., Alam, M.M., Ramli, M., Rafidi, M., 2017. Integrating ethical values into fraud triangle theory in assessing employee fraud: Evidence from the Malaysian banking industry. Journal of International Studies 10(2), 170-184.

Suh, J., Shim, H., Button, M., 2018. Exploring the impact of organizational investment on occupational fraud: Mediating effects of ethical culture and monitoring control. International Journal of Law, Crime and Justice 53(June), 46-55.

The Bank of Korea, 2011. Financial System in Korea, (In Korean). The Bank of Korea, Seoul.

Tillman, R., 2015. Bad banks Recurrent criminogenic conditions in the US commercial banking industry, in: Tillman, R., Barak, G. (Eds.), The Routledge International Handbook of the Crimes of the Powerful. Routledge, London, pp. 265-277.

Tipgos, M., 2002. why management fraud is unstoppable. The CPA Journal 72(12), 34-41.

Tunley, M., Button, M., Shepherd, D., Blackbourn, D., 2018. Preventing occupational corruption: utilising situational crime prevention techniques and theory to enhance organisational resilience. Security Journal 31(1), 21-52.

Vu, H.T., 2016. The Research of Factors Affecting the Effectiveness of Internal Control Systems in Commercial Banks-empirical Evidence in Viet Nam. International Business Research 9(7), 144-153.

Wells, J., 1997. Occupational Fraud and Abuse. Obsidian Pub. Co., Dexter. 
Wheeler, S., Rothman, M., 1982. The Organization as Weapon in White Collar Crime. Michigan Law Review 80(7), 1403-1426.

Wolfe, D.T., Hermanson, D.R., 2004. The Fraud Diamond: Considering the Four Elements of Fraud. CPA Journal 74(12), 38-42.

Wortley, R., 2010. Critiques of situational crime prevention, in: Fisher, B.S., Lab, S. (Eds.), Encyclopedia of Victimology and Crime Prevention. Sage, Thousand Oaks.

i See New Finance Society Institute (http://www.nfsi.or.kr/index.asp)

Table 1: Depository financial Institutions in South Korea and sample size

\begin{tabular}{|c|c|c|c|}
\hline Financial sector & Type & Subtype & Sample size \\
\hline \multirow{3}{*}{ Sector one } & \multirow{3}{*}{ Commercial banks } & Nationwide banks & $177(44.8 \%)$ \\
\hline & & & \\
\hline & & Regional banks & $28(7.1 \%)$ \\
\hline \multirow{4}{*}{ Sector two } & \multirow{3}{*}{ Credit institutions } & $\begin{array}{l}\text { Local agricultural \& fishery } \\
\text { cooperatives }\end{array}$ & $81(20.5 \%)$ \\
\hline & & Community credit cooperatives & $32(8.1 \%)$ \\
\hline & & Credit unions & $58(14.7 \%)$ \\
\hline & Savings institutions & Savings banks & $19(4.8 \%)$ \\
\hline Total & & & $395(100.0)$ \\
\hline
\end{tabular}




\begin{tabular}{|c|c|c|c|c|c|}
\hline Variables & $\mathrm{N}$ & mean & std. deviation & $\min$ & $\max$ \\
\hline Number of anti-fraud controls & 395 & 10.84 & 2.73 & 0 & 14 \\
\hline Perceived opportunity reduction & 395 & 3.50 & 0.86 & 1 & 5 \\
\hline Perceived management override & 395 & 3.12 & 1.14 & 1 & 5 \\
\hline Perceived collusion & 395 & 2.75 & 1.01 & 1 & 5 \\
\hline
\end{tabular}

Table 3: Correlation matrix

\begin{tabular}{lllll}
\hline & $\begin{array}{l}\text { Number of } \\
\text { anti-fraud } \\
\text { controls }\end{array}$ & $\begin{array}{l}\text { Perceived } \\
\text { opportunity } \\
\text { reduction }\end{array}$ & $\begin{array}{l}\text { Perceived } \\
\text { management } \\
\text { override }\end{array}$ & $\begin{array}{l}\text { Perceived } \\
\text { collusion }\end{array}$ \\
\hline $\begin{array}{l}\text { Number of } \\
\text { anti-fraud } \\
\text { controls }\end{array}$ & 1 & & & \\
\hline $\begin{array}{l}\text { Perceived } \\
\text { opportunity } \\
\text { reduction }\end{array}$ & $0.467^{* *}$ & 1 & 1 & 1 \\
\hline $\begin{array}{l}\text { Perceived } \\
\text { management } \\
\text { override }\end{array}$ & 0.023 & 0.025 & $0.550^{* *}$ & \\
\hline $\begin{array}{l}\text { Perceived } \\
\text { collusion }\end{array}$ & 0.020 & 0.064 & & 395 \\
\hline $\mathrm{N}$ & 395 & 395 & 395 & \\
\hline$* * p<0.01$ & & & & \\
\hline
\end{tabular}


Table 4: Results for the logistic regressions

(Each model reports the addition of incremental variables, $\mathrm{N}=395$ )

\begin{tabular}{|c|c|c|c|c|c|}
\hline & Variables & Model 1 & Model 2 & Model 3 & Model 4 \\
\hline & & $\begin{array}{l}\beta \\
\text { (Odds ratio) }\end{array}$ & $\begin{array}{l}\beta \\
\text { (Odds ratio) }\end{array}$ & $\begin{array}{l}\beta \\
\text { (Odds ratio) }\end{array}$ & $\begin{array}{l}\beta \\
\text { (Odds ratio) }\end{array}$ \\
\hline & Constant & $\begin{array}{l}-0.734^{*} \\
(0.480) \\
\end{array}$ & $\begin{array}{l}-1.163 \\
(0.313) \\
\end{array}$ & $\begin{array}{l}-0.324 \\
(0.723) \\
\end{array}$ & $\begin{array}{l}-0.855 \\
(0.425) \\
\end{array}$ \\
\hline \multirow{8}{*}{ 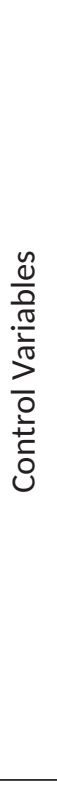 } & $\begin{array}{l}\text { IC/Support } \\
\text { department }\end{array}$ & $\begin{array}{l}1.121^{* * *} \\
(3.068)\end{array}$ & $\begin{array}{l}1.211^{* * *} \\
(3.357)\end{array}$ & $\begin{array}{l}1.314^{* * *} \\
(3.720)\end{array}$ & $\begin{array}{l}1.292^{* * *} \\
(3.641)\end{array}$ \\
\hline & Organizational size & $\begin{array}{l}1.146^{* *} \\
(3.146) \\
\end{array}$ & $\begin{array}{l}1.092^{* *} \\
(2.981) \\
\end{array}$ & $\begin{array}{l}1.244^{* *} \\
(3.469)\end{array}$ & $\begin{array}{l}1.320^{* *} \\
(3.742)\end{array}$ \\
\hline & $\begin{array}{l}\text { Financial } \\
\text { institution type }\end{array}$ & & & & \\
\hline & Regional banks & $\begin{array}{l}-0.123 \\
(0.884)\end{array}$ & $\begin{array}{l}-0.090 \\
(0.904)\end{array}$ & $\begin{array}{l}-0.021 \\
(0.979)\end{array}$ & $\begin{array}{l}0.046 \\
(1.047)\end{array}$ \\
\hline & Agri-fishery coop. & $\begin{array}{l}-0.543 \\
(0.581) \\
\end{array}$ & $\begin{array}{l}-0.499 \\
(0.607) \\
\end{array}$ & $\begin{array}{l}-0.603 \\
(0.547) \\
\end{array}$ & $\begin{array}{l}-0.616 \\
(0.540) \\
\end{array}$ \\
\hline & $\begin{array}{l}\text { Community credit } \\
\text { coop. }\end{array}$ & $\begin{array}{l}-2.599^{* *} \\
(0.074)\end{array}$ & $\begin{array}{l}-2.536^{* *} \\
(0.079)\end{array}$ & $\begin{array}{l}-2.713^{* *} \\
(0.066)\end{array}$ & $\begin{array}{l}-2.669^{* *} \\
(0.069)\end{array}$ \\
\hline & Credit unions & $\begin{array}{l}-1.881^{* * *} \\
(0.152)\end{array}$ & $\begin{array}{l}-1.818^{* * *} \\
(0.162) \\
\end{array}$ & $\begin{array}{l}-1.865^{* * *} \\
(0.155)\end{array}$ & $\begin{array}{l}-1.706^{* *} \\
(0.182) \\
\end{array}$ \\
\hline & Savings banks & $\begin{array}{l}-0.430 \\
(0.651)\end{array}$ & $\begin{array}{l}-0.409 \\
(0.665) \\
\end{array}$ & $\begin{array}{l}-0.472 \\
(0.624) \\
\end{array}$ & $\begin{array}{l}-0.546 \\
(0.579) \\
\end{array}$ \\
\hline \multirow{4}{*}{ 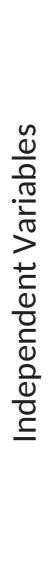 } & $\begin{array}{l}\text { Number of } \\
\text { anti-fraud } \\
\text { controls }\end{array}$ & & $\begin{array}{l}0.039 \\
(1.039)\end{array}$ & $\begin{array}{l}0.082 \\
(1.085)\end{array}$ & $\begin{array}{l}0.085 \\
(1.089)\end{array}$ \\
\hline & $\begin{array}{l}\text { Perceived } \\
\text { opportunity } \\
\text { reduction }\end{array}$ & & & $\begin{array}{l}-0.390^{*} \\
(0.677)\end{array}$ & $\begin{array}{l}-0.385^{*} \\
(0.681)\end{array}$ \\
\hline & $\begin{array}{l}\text { Perceived } \\
\text { management } \\
\text { override }\end{array}$ & & & & $\begin{array}{l}0.329 * \\
(1.390)\end{array}$ \\
\hline & $\begin{array}{l}\text { Perceived } \\
\text { collusion }\end{array}$ & & & & $\begin{array}{l}-0.216 \\
(0.805)\end{array}$ \\
\hline \multicolumn{2}{|c|}{ Model significance } & 0.000 & 0.000 & 0.000 & 0.000 \\
\hline \multicolumn{2}{|c|}{$\begin{array}{l}\text { Pseudo R square } \\
\text { (Nagelkerke) }\end{array}$} & 0.311 & 0.313 & 0.327 & 0.345 \\
\hline \multicolumn{2}{|c|}{ Classification Accuracy } & 0.722 & 0.724 & 0.734 & 0.744 \\
\hline
\end{tabular}

${ }^{* * *} p<0.001,{ }^{* *} p<0.01,{ }^{*} p<0.05$, 